\title{
Using Delphi Technique and the P-Process model to assess health communication programmes in Nigeria
}

\author{
Authors: \\ Abimbola Onigbanjo- \\ Williams $\mathbf{s}^{1,2}$ \\ Stella Iwuagwu ${ }^{3}$

\begin{abstract}
Affiliations:
${ }^{1}$ Department of Mental Health, Johns Hopkins

Bloomberg School of Public

Health, United States

${ }^{2}$ Department of

State University of New

Jersey, United States

${ }^{3}$ School of Health Sciences, Cleveland State University, United States
\end{abstract} \\ Epidemiology, Rutgers the
}

\section{Correspondence to:}

Abimbola Onigbanjo-Williams

\section{Email:}

abolawilliams@yahoo.com

\section{Postal address:}

School of Public Health, 683 Hoes Lane West, Piscataway, NJ 08854, United States

\section{Dates:}

Received: 15 May 2015

Accepted: 11 Sept. 2015

Published: 12 Oct. 2015

How to cite this article: Onigbanjo-Williams, A. \& Iwuagwu, S., 2015, 'Using Delphi Technique and the P-Process model to assess health communication programmes in Nigeria', African Evaluation Journal 3(2), Art. \#157, 8 pages. http://dx.doi.org/10.4102/ aej.v3i2.157

\section{Copyright:}

C 2014. The Authors. Licensee: AOSIS

OpenJournals. This work is licensed under the Creative Commons Attribution License.
Strategic health communication is an integral part of the programmes and development that influence decisions regarding health. Health communication is often integrated into public health interventions to improve programme outcomes. Despite the massive donor funding for public health programmes in Nigeria, there is limited information on the current status of health communication programmes. This study aims to identify the knowledge gaps, describe the future direction and highlight recommendations for strengthening health communication programmes in Nigeria. Using a purposive sampling methodology, the online study used a two-staged Delphi Technique and the P-Process model to collect data from key stakeholders. Stakeholders included donors, government, civil society organisations, research institutions, education and training institutions, and communities. Descriptive analysis was done using SPSS. Capacity-building gaps were identified and a conceptual framework was developed. These gaps included: the low technical capacity of stakeholders in health communication, limited resources for organisations to implement activities, the lack of a strategic framework to guide the implementation of health communication programmes, and minimal collaboration with stakeholders. These findings provided an insight into the current state of health communication programmes, which is mainly at the programme activity level. In this study, the findings highlighted a critical need to develop and strengthen health communication programmes in Nigeria with a view to improving performance and health outcomes and optimising health service delivery in the country.

\section{Introduction}

\section{Background}

Nigeria ranks as the most populous country in Africa and the seventh most populous in the world with an estimated population of more than 177 million (Population Reference Bureau 2014). The country also ranks 152 out of 187 countries with the worst health indicators (UNDP 2014). Despite its vast oil wealth, Nigeria receives development funds from several international and multilateral donor agencies to tackle its various health problems. Many of these donor support efforts have yielded positive results in almost all fields of public health practice such as family planning, HIV and/or AIDS, breast cancer and, malaria. These positive results have been associated with the integration and adoption of health communication as a strategy for behaviour change (Krenn \& Limaye 2009).

Health communication encompasses the study and use of communication strategies to inform and influence individual and community decisions that enhance health. Health communication links the domains of communication and health, and it is increasingly being recognised as a necessary element of efforts to improve personal and public health (Jackson \& Duffy 1998; National Cancer Institute 1989; Piotrow et al. 1997). By extension, health communication interventions are designed to influence individual and community knowledge, attitudes and practices (KAP) which affect health behaviours (Thomas 2006). Such interventions are therefore expected to require detailed advance planning, with specific focal activities clearly outlined for the achievement of their goals. Health communication, at all levels (both interpersonal and mass media) and across different structures (individual, institutions and systems) therefore plays a major role in promoting a healthy community.

Owing to the enormous potential for improving the impact of public health interventions, many public health programmes have used effective communication channels to initiate and sustain behaviour change. They have relied on culturally acceptable information, education and communication (IEC) and behaviour change communication (BCC) materials. Much attention has been devoted to the potential uses of the mass media within the field of public health to modify attitudes, shape behaviour and generally persuade audiences to protect their health (Amezcua et al. 1990; Hornik 1989; Wallack 1989). Several authors (Acharya et al. 2015; Bekalu et al. 2014) 
have shown the complimentary benefits of using electronic media and open media to deliver health information, increase awareness and influence community norms. The 'traditional' media platforms (radio, television and print) have been shown to be important sources of information on health issues for people living in rural communities in Nigeria (Brieger 1990). Furthermore, mobile technology has lately played an increasing role in the delivery of health information messages. Such messages have been suggested to improve the health and lives of vulnerable individuals (Pyramid-Research 2010).

\section{Literature Review}

In view of the many impediments to a healthy life, lowresource settings need a systematic health communication strategy to guide their decisions in ensuring healthy living in individuals as members of society (Amuseghan, Ayenigbara \& Orimogunje 2010). The essential element in health communication programmes is a scientific approach that builds on conceptual models in behavioural sciences, persuasion theory, social learning and social marketing to achieve realistic objectives (Chaffe 1982; Piotrow et al. 1997). Here, communication persuasion theory has been used to examine consumer behaviour in response to messages, especially mass media. This model has been used to guide public health communication and has traditionally focused on small-scale and at-risk populations (Corcoran 2007). Social learning and social marketing, another model, emphasises the importance of peer influences on behaviour and posits that adolescents learn both by direct experience and by observation (Bandura 1977).

The capacity of organisations and societies to manage their affairs successfully is the core objective of strategic health communication programmes, which is to promote behaviour change. Adequate country capacity is one of the critical missing factors in current efforts to meet the Millennium Development Goals (MDGs) (OECD 2006). It is vital that organisations continually nurture and seek decisive ways to strengthen and evaluate a system that fosters individual participation and organisational and institutional capacity to conduct effective and efficient health communication programmes.

The evolution of the types of programme and communications programme to reach larger audiences using radio and/or television has advanced over the years (Bertrand et al. 2006). A systematic literature search was conducted by Bertrand et al. (2006) to evaluate the effects of mass communication programmes on HIV and/or AIDS-related knowledge, attitudes and behaviours in developing countries. Of the 24 articles reviewed, 5 used television (with supporting media or alone); 7 employed radios (with supporting media or alone) and the remaining 12 used 'small media' (with or without interpersonal communication such as a group meeting or counselling). The majority of the evaluations of mass media programmes published from 1990 to 1999 focused on small media (10 of 13 studies). Clearly, this shows the impact of mass communication and health communication on influencing behaviour change.

Okidu (2014) analysed HIV and/or AIDS communication models in Nigerian newspapers. This analysis was done based on the need for communication models to focus on the activity rather than on cognitive indicators in order to achieve the desired improvements in health behaviours and outcomes. The cognitive model of BCC assumes that the individual reason provides the impetus for human action (Nzioka 1996) and interprets and analyses health behaviours at the individual level (Okidu 2014). Examples of cognitive models are the AIDS Risk Reduction Model (ARRM), the Health Belief Model, and the theory of reasoned action (Okidu 2014). The activity model views behavioural outcomes as a product of the individual's context and argues that human activity is complex, socially bound, driven and not simply the sum of individual actions (Engeström 1999).

Past failures of HIV and/or AIDS communication efforts in low and middle income countries (LMICs) have been attributed to an emphasis on cognitive indicators. The study showed that the activity model of HIV / AIDS communication dominates the four mainstream Nigerian newspapers studied. However, it is worth noting the limited number of editorials and feature articles, which normally are capable of stimulating debate and fostering a social environment in which AIDS is addressed in a spirit of openness. For a country that has the third largest number of people living with HIV and/or AIDS globally, one would expect the mass media deliberately to play an instrumental role and to adopt a more active position in the battle against the disease by engaging in in-depth discourse on HIV and/or AIDS (Okidu 2014).

Many studies consider behavioural changes to be the most important outcome of communication campaigns, but communication most frequently works as an indirect contributor to behaviour change outcomes (AbbatangeloGray, Cole \& Kennedy 2007; Contento 2008; Rowe et al. 2011). For example, Acharya et al. (2015) conducted a community-based cross-sectional study in Nepal to examine the association between selected antenatal care services and mass media exposure after adjusting for other independent variables. The study reported a positive influence of mass media on the use of antenatal care services in Nepal. Another study by Moreno and Whitehill (2014) assessed the influence of social media on alcohol use in adolescents and young adults. The study found that online displays of pro-alcohol messages are correlated to offline alcohol behaviour and risky drinking (Moreno \& Whitehill 2014).

Undoubtedly, health communication, including mass communication, has an influence on behaviour change and therefore has an impact on public health interventions. Bekalu et al. (2014) found that media use was generally associated with low levels of HIV-related stigma and this may have 
the potential to minimise the gap between individuals with high and low educational levels (Bekalu et al. 2014). Also, recognising the need to ensure that institutions or systems have the capacity to implement health communication programmes, it is critical that a valid, up-to-date and relevant assessment of the status of health communication programmes in Nigeria is conducted. It is also important that institutions and stakeholders are clear about the context of what knowledge gaps are common across health communication programmes. As a prerequisite to strengthening behaviour change in health programmes, it is critical that institutions have the capacity to implement communication programmes targeted at public health interventions. It is also important to understand the body of knowledge and best practices in health communication in different institutions and diverse contexts, and to know what works well and what not.

Less is known about the current situation, including the knowledge gaps in health communication programmes, in Nigeria. This is because studies have focused on BCC at programme level as opposed to assessing the state of health communication in Nigeria generally. Consequently, this paper focuses on assessing the knowledge gaps in the country's health communication programmes. In addition, using the P-Process ${ }^{1}$ this paper provides future direction for the state of health communication programmes in Nigeria. Using two unique evaluation and assessment tools, this study uses an innovative approach to provide a snapshot of the current status and future directions of health communication in the country. The findings in this paper will be of interest to stakeholders, including researchers, donors and bilateral agencies, which have to provide strategic guidance and direction to health communication programmes in lowresource settings.

\section{Research Method and Design Setting}

The study focused on institutions that are implementing health communication programmes in Nigeria. Although the study targeted all institutions implementing health communication programmes in the country, the majority of the participants are resident in the Federal Capital Territory (FCT). These institutions include representatives of donor agencies, government ministries, civil society organisations (CSOs), Non-governmental organisations (NGOs), research organisations and academic institutions.

\section{Design}

The Delphi Technique was used to engage an expert panel in two rounds of data collection, which included qualitative and quantitative components. The Delphi Technique is useful when there is a need to achieve consensus from geographically dispersed experts (Keeney, Hasson \& Mckenna 2001). In the first round, an open-ended questionnaire was used to solicit information on health communication from experts through sequential interactions. Preliminary analysis of the findings from this phase was developed into a well-structured questionnaire, which formed the basis for the second round. In the second round, the participants were asked to review summary findings from the first round and rank them according to 'agreed' or 'disagreed' options. They were asked to state the rationale for their ranking and this gave them the opportunity to revise their judgements. During this phase, the list of issues and their ratings were shared with the group to enable the participants to revise their judgement where necessary. Consensus amongst the participants, also known as the level of agreement, was aggregated based on individual judgements.

The P-Process is a five-step process of communication and strategic design that involves, as key components, situational analysis, strategic design, development and testing, implementation, monitoring and evaluation, replanning with participation, and capacity strengthening (Health Communication Capacity Collaborative 2013). ${ }^{2}$ The P-Process was used based on its diversity in developing and addressing a wide range of public health programmes. The model has been used to develop health communication programmes addressing a wide range of topics such as encouraging safer sexual behaviour to prevent HIV transmission, promoting child survival, reducing maternal mortality, increasing contraceptive prevalence, preventing infectious diseases, and promoting environmental health (Health Communication Capacity Collaborative 2013).

\section{Procedure}

A purposive sampling methodology was used to recruit experts (professional staff and top management officials) into the study by conducting a stakeholder identification exercise to identify technical experts conversant with health communication. This exercise was conducted by listing institutions that are implementing health communication programmes. This list was further narrowed by sector representation. Afterwards, the email addresses of selected experts were obtained through an online search, professional contacts and reference materials, and a request for participation was sent out to a total of 50 participants. Each participant was sent an email to test email functionality, to request their consent, and to determine their eligibility. The inclusion criteria for participation in the study were: access to the Internet, knowledge of health communication, and a willingness to complete the two rounds of assessment.

The study used a pretested, self-administered questionnaire with both open- and closed-ended questions. The questionnaire was administered using survey monkey; an online data collection tool to explore issues related to health communication programmes (e.g. capacity building, training, collaborative efforts, information needs and communication tools). The closed-ended questions were ranked according to the scale 'Definitely to a little extent' 
as 1, 'probably to a little extent' as 2, 'undecided' as 3, 'probably to a great extent' as 4 and 'Definitely to a great extent' as 5. Participants' email addresses were uniquely tied to the survey to facilitate the tracking of participants who had responded to the survey. In each round of data collection, the participants were asked to scale each statement according to their degree of agreement and to comment on statements. The degree of agreement provided an opportunity for participants to scale each statement independently of other participants.

The participants were also asked to analyse the current state of Nigeria's health communication programmes using a designed template. The template, as highlighted in Figure 2, was designed using the P-Process (Health communication capacity collaborative 2013). The template includes arrows in ascending order from level 1 to 5: low (1), low to moderate (2), moderate (3), moderate to high (4), and sustainable (5). The participants were asked to move arrows in varying degrees to where they thought capability indicators described Nigeria's current health communication status. The capability indicators included organisation vision, resources, communication skills, management, and teamwork. For the purposes of the study, 'vision' was defined as a statement of what the programme wants to achieve in future. Resources focused on the availability of human, materials and financial assets. Communication skills included organisations with personnel trained in communication, opportunities for capacity building and the availability of resources. Management refers to the existing structures available in organisations, including administrative structures and availability of management positions working on health communication programmes. Teamwork focused on the available opportunities for personnel to work together in harmony in order to achieve the desired objectives.

The study was approved by the Ethics Committee of the Johns Hopkins School of Public Health Center for Communication Program. In addition, some degree of anonymity (names of respondents were withheld and represented by the type of organisation) was provided for their individual contributions during the two rounds of the survey. The participants were assured of their rights to privacy and of the confidentiality of information and the data provided. Informed consent was collected through an email sent to the participants prior to the initiation of the research. Data collection lasted for a period of one month. Intermittent reminders were also sent to those who were yet to respond during the course of the data collection phase. In minimising attrition, a key number of mechanisms were adopted. These included short followup periods between survey rounds, issuing reminders by email and ensuring that the participants were fully informed about the study.

\section{Analyses}

Quantitative analysis using SPSS statistical software was used to provide descriptive statistics that described the current status of health communication programmes in the country. These included calculations of percentages, mean scores of the levels of agreement for each statement and the standard deviation (SD) of each statement. The mean scores highlighted in Table 2 depict a range in value from 1 to 5, whilst the status column provides an interpretation of the scores. Scores of less than 2.9 are regarded as fair (1) to poor agreement 3 reflects moderate agreement, and scores above 3 highlight a substantial to almost perfect agreement (5).

\section{Results \\ Outline of the results}

A total of 36 experts participated in the online survey: research institutions $(2.8 \%)$, community $(11.1 \%)$, education and training $(13.9 \%)$, donor $(16.7 \%)$, government $(16.7 \%)$ and CSOs/NGOs (38.9\%). The majority of the respondents were from CSOs/NGOs. These estimates are highlighted in Table 1.

Table 2 shows the responses of the participants on the matter of gaps in health communication programmes. A high level of agreement was observed amongst participants who felt that donors provided technical support in implementing health communication programmes. The table also highlights the fact that donors have clear policies in place for implementing health communication programmes. Furthermore, the participants also felt that the government had minimal collaboration $(<3.0)$ with ministries and an inadequate allocation of resources to health and communication programmes. The participants rated research institutions low in providing support to the health communication programmes in the country $(<2.6)$

On the other hand, they felt that the mass media provided support for health communication, but ranked commercial advertising and production agencies low (2.3). The participants ranked accredited training institutions low $(<2.3)$ in offering bachelors and graduate degrees, and shortterm training programmes in health communication. Both communities and households were rated low (1.7-2.7) in literacy and exposure to health communication programmes.

Figure 1 summarises the mean scores of the respondents by technical capacity to implement health communication programmes. The least capacity was seen with research and with education and training institutions (2.5) and the highest was amongst donors (3.0). This clearly shows that donors were regarded as having the technical capacity to implement health communication programmes.

TABLE 1: Distribution of expert groups.

\begin{tabular}{lcc}
\hline Target audience & Sample size $(\boldsymbol{n})$ & Percentage \\
\hline Donors & 6 & 16.7 \\
Government & 6 & 16.7 \\
CSO/NGO & 14 & 38.9 \\
Research institutions & 1 & 2.8 \\
Education and training & 5 & 13.9 \\
Community & 4 & 11.1 \\
\hline
\end{tabular}


TABLE 2: Ranking $\dagger$ of mean scores and level of agreement of necessary actions in facilitating capacity strengthening by expert groups.

\begin{tabular}{|c|c|c|c|c|}
\hline Respondent & Necessary actions of relevant actors in facilitating capacity strengthening & Mean score & SD & $\begin{array}{l}\text { Level of } \\
\text { agreement }\end{array}$ \\
\hline \multirow[t]{6}{*}{ Donors } & Do donors have a clear policy that supports health communication $(\mathrm{HC})$ ? & 3.3 & 1.2 & High \\
\hline & Do donors allocate sufficient resources to $\mathrm{HC}$ ? & 2.7 & 1.3 & Low \\
\hline & Do donors facilitate technical support in $\mathrm{HC}$ ? & 3.0 & 1.3 & Undecided \\
\hline & Do donors have a clear policy supporting capacity strengthening in $\mathrm{HC}$ ? & 2.9 & 1.3 & Undecided \\
\hline & Allocate sufficient resources to capacity strengthening in $\mathrm{HC}$. & 2.6 & 1.3 & Low \\
\hline & Facilitate technical support in capacity strengthening for $\mathrm{HC}$. & 2.6 & 1.3 & Low \\
\hline \multirow[t]{7}{*}{ Government } & $\begin{array}{l}\text { Does Ministry of Health (MOH) strongly collaborate with Ministries of Information and Communication, } \\
\text { Education, and Women Affairs and Social Development on HC? }\end{array}$ & 2.4 & & Low \\
\hline & Does the $\mathrm{MOH}$ have a clear policy supporting $\mathrm{HC}$ ? & 2.6 & 1.2 & Low \\
\hline & Does $\mathrm{MOH}$ allocate sufficient resources to $\mathrm{HC}$ ? & 2.0 & 1.0 & Low \\
\hline & Does $\mathrm{MOH}$ collaborate with commercial advertising and social marketing agencies on $\mathrm{HC}$ ? & 2.5 & 1.1 & Low \\
\hline & Does $\mathrm{MOH}$ collaborate with universities/academic institutions that engage in $\mathrm{HC}$ ? & 2.6 & 1.2 & Low \\
\hline & Does $\mathrm{MOH}$ collaborate with civil society and training institutions that engage in $\mathrm{HC}$ ? & 2.9 & 1.3 & Undecided \\
\hline & $\begin{array}{l}\text { Does } \mathrm{MOH} \text { provide strong support to specialised agencies (HIV, malaria, TB, FP, MNCH, nutrition, etc.) in their } \\
\text { HC efforts? }\end{array}$ & 3.1 & 1.4 & Undecided \\
\hline \multirow{5}{*}{$\begin{array}{l}\text { Civil society } \\
\text { organisations }\end{array}$} & Do NGOs, CBOs, FBOs actively support $\mathrm{MOH}$ in its $\mathrm{HC}$ efforts? & 3.6 & 1.2 & High \\
\hline & $\begin{array}{l}\text { Do NGOs collaborate with commercial advertising and production agencies provide support to HC efforts of } \\
\text { MOH? }\end{array}$ & 2.5 & 1.0 & Low \\
\hline & Do CSOs collaborate with social marketing agencies provide support to $\mathrm{HC}$ efforts of $\mathrm{MOH}$ ? & 2.2 & 0.8 & Low \\
\hline & Do CSOs collaborate with the private sector to provide support to $\mathrm{HC}$ efforts of $\mathrm{MOH}$ ? & 2.7 & 0.8 & Low \\
\hline & Do CSOs collaborate with mass media institutions to provide support to $\mathrm{HC}$ efforts of $\mathrm{MOH}$ ? & 3.5 & 1.1 & High \\
\hline \multirow{2}{*}{$\begin{array}{l}\text { Research } \\
\text { institutions }\end{array}$} & Do research institutions provide research support to $\mathrm{HC}$ efforts? & 2.6 & 1.1 & Low \\
\hline & Do research institutions provide support to strengthen $\mathrm{HC}$ capacities? & 2.5 & 1.1 & Low \\
\hline \multirow[t]{4}{*}{$\begin{array}{l}\text { Education and } \\
\text { training }\end{array}$} & $\begin{array}{l}\text { Do accredited academic institutions offer bachelor and graduate degrees and short-term training programmes } \\
\text { in HC? }\end{array}$ & 2.0 & 1.1 & Low \\
\hline & $\begin{array}{l}\text { Graduates of bachelor degrees in health communication (if any) demonstrate acceptable novice } \\
\text { competencies in HC. }\end{array}$ & 2.3 & 0.9 & Low \\
\hline & Graduates of advanced degrees in health communication (if any) demonstrate proficient competencies in HC. & 3.0 & 1.1 & Undecided \\
\hline & Do local health communication professionals demonstrate expert competencies in $\mathrm{HC}$ ? & 2.6 & 1.1 & Low \\
\hline \multirow[t]{3}{*}{ Community } & Do community institutions promote health literacy? & 2.7 & 1.4 & Low \\
\hline & Are communities engaged in $\mathrm{HC}$ activities? & 2.9 & 1.2 & Undecided \\
\hline & Are communities exposed to $\mathrm{HC}$ programmes? & 2.9 & 1.2 & Undecided \\
\hline
\end{tabular}

†, The mean score was ranked with increasing power from 'extremely low' as 0-0.9, 'low' as 1.0-2.8, 'undecided' as 2.9-3.1, 'high' as 3.2-4.0, and 'extremely high' as 4.1-5.0.

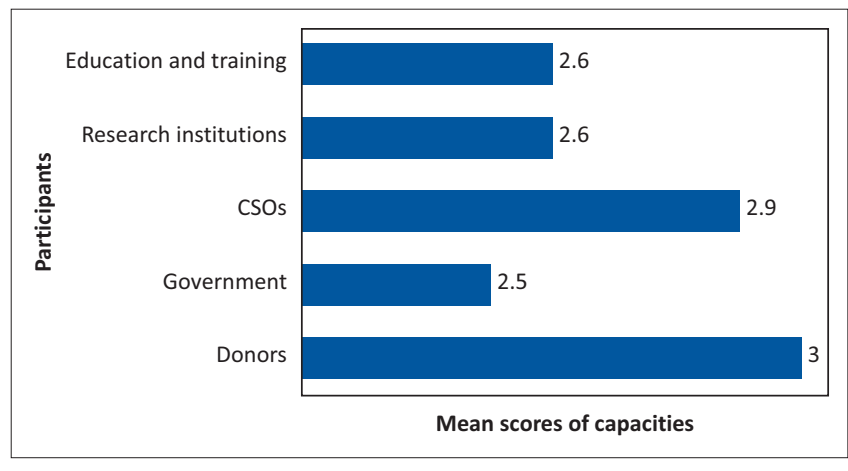

FIGURE 1: Mean scores of expert capacities to implement health communication programme.

Figure 2 represents the current status of health communication in Nigeria. In the Figure, the arrows show the direction from a low to moderate level (level 2). The vision of health communication ranges from level 1 (low) to level 2 (moderate), with most health communication developed for programme activities and campaigns. The country lacks a national health communication strategic framework. Resources are still low (level 2) and depend on external assistance or funding. Communication skills, management and teamwork are barely at level 3.
Experts were asked to offer recommendations for strengthening health communication programmes in Nigeria. Table 3 shows a list of the recommendations made by the participants, which included strategies and skills in advocacy, education, strategies/structures, collaborations and resources to strengthen capacity, and knowledge on health communication programmes in Nigeria.

\section{Discussion}

The survey provides insight into the current state and future directions for health communication programmes in Nigeria. The survey employed an email-based Delphi Technique to solicit responses and recommendations from a heterogeneous sample of experts $(n=36)$. The study used the P-Process to assess the current situation of health communication in Nigeria. These techniques were selected based on the geographical distance of the participants, the limited cost of recruiting participants and the high speed of data collection. The survey tool was designed to produce reliable information from a diverse range of technical experts working in health institutions. As such, it produced rich information on the current state of the health communication needs in the country. Perhaps most important amongst 


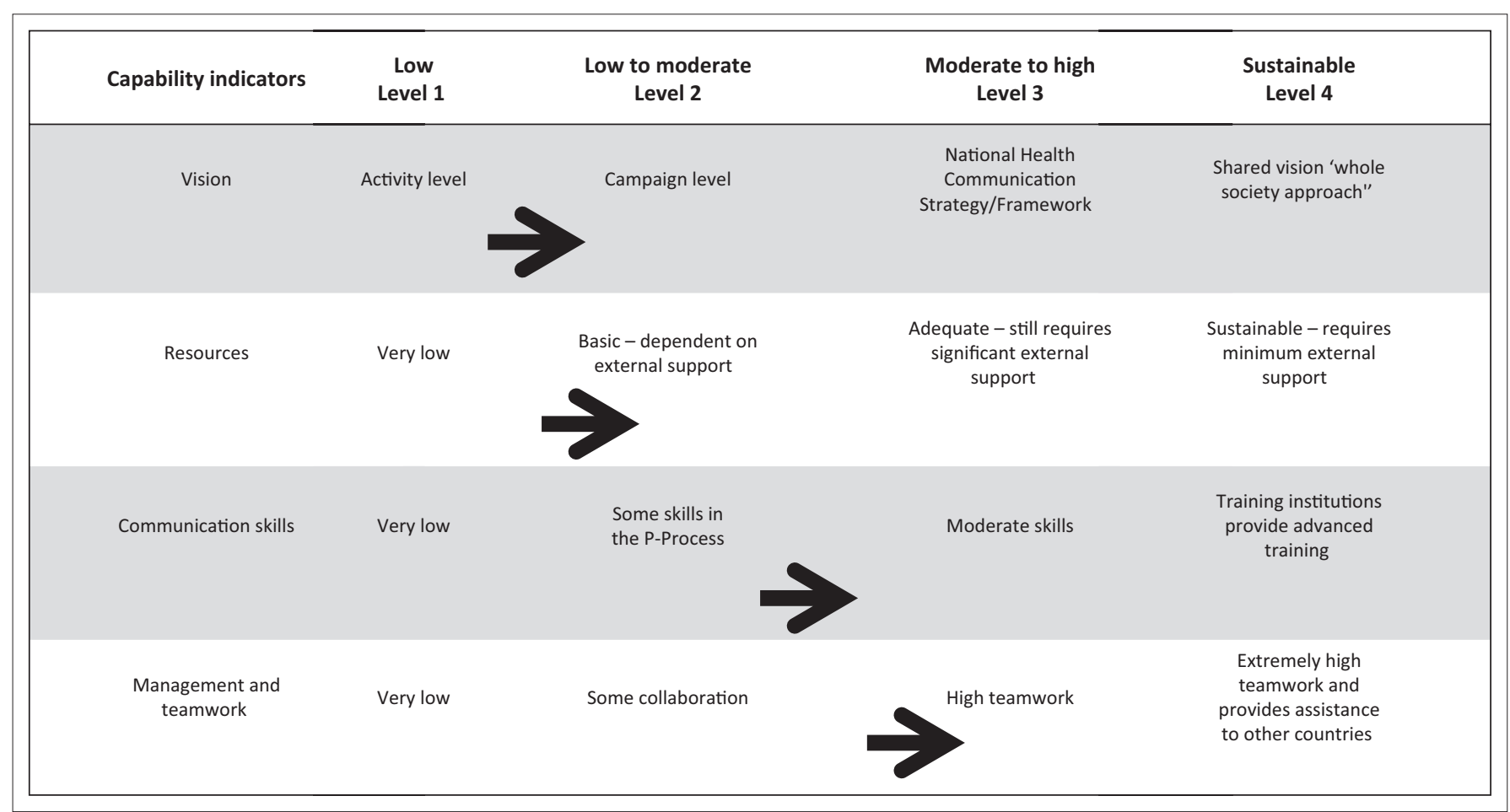

FIGURE 2: The current status of institutions implementing health communication programmes in Nigeria.

TABLE 3: Participants recommendations to strengthen capacity building needs of health communication programs in Nigeria.

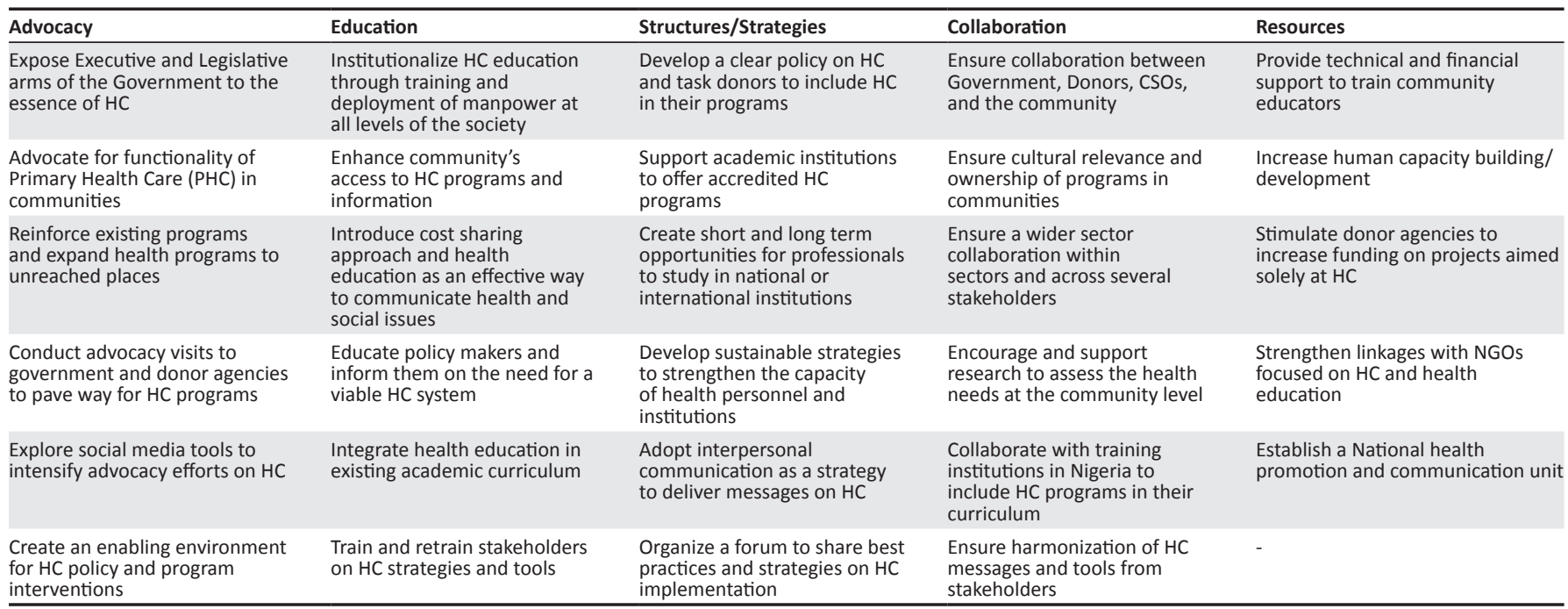

the contributions are the insights into areas for capacity strengthening in health communication programmes.

To our knowledge, this is a novel finding that seeks to assess the technical and knowledge capacity of health communication programmes in Nigeria. Having identified the knowledge gaps of health communication programmes in Nigeria and this paper can be used as a resource for designing future capacity-building initiatives for health institutions and others alike involved in the delivery of services to various communities. We found evidence of low levels of capacity in health communication programmes and health-related organisations.
In achieving this, key constraints were identified to provide a more solid foundation for the sustainability of health outcomes. These constraints include low technical capacity to implement health communication programmes, limited resources to fund and implement activities, and the lack of a strategic framework to guide the implementation of health communication programme in the country. The study shows that the predominant type of health communication programme in Nigeria lie somewhere between the programme activity and the campaign level. In addition, institutions implementing health communication programmes depend to some extent on external support, have moderate communication skills even though some P-Process 
communication skills are used in programmes, and maintain a high level of teamwork with stakeholders. Guided efforts still need to be made to transform and strengthen Nigeria's health systems into a more impressive and sustainable structure that includes health communication programmes at all levels.

Whilst not conclusive, the results from this study suggest a strong need to strengthen the capacity of health communication programmes in Nigeria. Also, the results have shown the necessity to develop sustainable and highimpact health communication programmes. Consequently, concerted effort needs to be made to strengthen the capacity building of health communication programmes and to ensure collective and collaborative efforts amongst the sector's stakeholders and institutions.

\section{Limitations of the study}

Although this study contributes to the existing literature on health communication, it has a number of limitations. First of all, this is a Delphi survey and its design does not allow for more transparency than face-to-face meetings. In addition, the technique has some limitations with anonymity and may lead to a lack of accountability because the responses cannot be traced back to individuals (Sackman 1975). In addition, a consensus approach can lead to a diluted version of the best opinion and the result represents the lowest common denominator (Powell 2003). The credibility of the study is threatened; factors leading to this include the level of panel expertise, the number of survey rounds, questionnaire development, analysis and the achievement of consensus. Also, it was difficult to maintain active participation by the respondents the whole way through the study, and so it suffered from moderately high attrition rates of $30.6 \%$ in round 2, down from an initial survey response rate of $90 \%$. The sample size is low and comprised mostly participants from NGOs and CSOs. This placed a limitation on the generalisation of findings to all health communication programmes in the country. Finally, in this study, the participants were required to have access to the Internet in order to complete the online survey. This approach was chosen to increase the timeliness and ease of access to the questionnaire. However, this approach limited participants who have none or limited access to a reliable Internet source.

\section{Recommendations}

The findings from the research suggest a need for institutions (research organisations, education and training, donors, and the government) to work with one another in order to develop structures and strategies that will strengthen the health communication programmes in Nigeria. These structures and strategies could include components of advocacy to key stakeholders, institutionalising health communication through training, developing clear policies on health communication and mobilising financial and technical resources to strengthen health communication programmes in the country. Several strategies that could be employed to strengthen the capacity of these programmes include providing technical assistance and specialised training to health institutions to strengthen their skills in developing, implementing and evaluating health communication programmes.

The provision of subsidised, tailored courses in health communication and in management for health communicators and other health organisations are also important strategies for consideration. Furthermore, having specialised bachelor and graduate degree programmes in health communication is very important. Since the study results showed a low collaboration with the Federal Ministry of Health (FMoH), there is a need for the $\mathrm{FMoH}$ to develop a national strategy and policy on health communication programmes. This will contribute towards integrating accountability mechanisms to ensure that health institutions are integrating effective and efficient strategies into their health communication programmes.

\section{Conclusion}

Despite these limitations, this study contributes to a broader understanding of the capacity-building needs of health communication programmes in Nigeria. The study identified the knowledge gaps, described the future directions and highlighted recommendations for strengthening these programmes. Clearly, the current status of the communication programmes is that they are still at the activity level and that gaps do exist. In conclusion, the findings suggest that there is a great need to strengthen the capacity-building activities of health communication programmes through advocacy, resources, education, structures and collaboration amongst key stakeholders. Further research would need to investigate in depth the health communication needs of the health sectors in Nigeria.

\section{Acknowledgements}

We would like to thank the institutions and organisations that gave of their time to share their views. We are also grateful to the Hubert Humphrey Fellowship at Johns Hopkins Bloomberg School of Public Health and the Center for Communications Program (CCP) at the Bloomberg School of Public Health. Our gratitude must also be expressed to Dr Benjamin Lozare from the CCP for his technical guidance in the development and implementation of the survey, and for supervising the project design. Finally, we are grateful to Dr Olusesan Makinde for assisting us in reviewing this paper.

\section{Competing interests}

The authors declare that they have no financial or personal relationship(s) that may have inappropriately influenced them in writing this article. 


\section{Authors' contributions}

A.O.W. (Johns Hopkins Bloomberg School of Public Health and Rutgers the State University of New Jersey) contributed to the implementation of the study design and the conceptualisation and writing of this article. S.I. (School of Health Sciences, Cleveland State University) provided leadership in the introduction and background sections of this article.

\section{References}

Abbatangelo-Gray, J., Cole, G.E. \& Kennedy, M.G., 2007, 'Guidance for evaluating mass communication health initiatives: Summary of an expert panel discussion sponsored by the Centers for Disease Control and Prevention', Evaluation \& The Health Professions 30, 229-253. PMID: 17693617.

Acharya, D., Khanal, V., Singh, J.K., Adhikari, M. \& Gautam, S., 2015, 'Impact of mass media on the utilization of antenatal care services among women of rura community in Nepal', BMC Research Notes 8, 345. http://dx.doi.org/10.1186/ s13104-015-1312-8

Amezcua, C., Mcallister, A., Ramirex, A. \& Espinoza, R., 1990, 'A su salud: Health promotion in a Mexican-American border community', in N. Bracht (ed.), Health promotion at the community level, pp. 257-277, Sage, Newbury Park, CA.

Amuseghan, S.A., Ayenigbara, G.O. \& Orimogunje, T., 2010, 'Language and health communication strategies towards effective public health communication programmes in Nigeria', Journal of Media and Communication Studies 2, 111-117.

Bandura, A., 1977, Social learning theory, General Learning Press, New York.

Bekalu, M.A., Eggermont, S., Ramanadhan, S. \& Viswanath, K., 2014, 'Effect of media use on HIV-related stigma in sub-Saharan Africa: A Cross-Sectional Study',
PLOS ONE 9, e100467. PMID: 24945251, http://dx.doi.org/10.1371/journal. pone.0100467

Bertrand, J.T., O'Reilly, K., Denison, J., Anhang, R. \& Sweat, M., 2006, 'Systematic review of the effectiveness of mass communication programs to change HIV/ AIDS-related behaviors in developing countries', Health Education Research 21 , 567-597. PMID: 16847044.

Brieger, W., 1990, 'Mass media and health communication in rural Nigeria', Health Policy and Planning 5, 77-81. http://dx.doi.org/10.1093/heapol/5.1.77

Chaffe, S.H., 1982, 'Mass media and interpersonal channels: Competitive, convergent, or complementary?', in G. Gumbert \& R. Cathcart (Hrsg.), Inter/Media: Interpersonal Communication in a Media World (2. Auflage, S. 57-77), Oxford University Press, New York and Oxford.

Contento, I.R., 2008, 'Nutrition education: Linking research, theory, and practice', Asia Pacific Journal of Clinical Nutrition 17, 176-179. PMID: 18296331.

Corcoran, N., 2007, Theories and models in communicating health messages [Corwin. com], viewed 28 August 2015, from http://www.corwin.com/upm-data/13975 Corcoran_CChapter_1.pdf.

Engeström, Y., 1999, Activity theory and individual and social transformation, Cambridge University Press, Cambridge.
Health Communication Capacity Collaborative, 2013, The P-Process. Five steps to strategic communication, November, Health Communication Capacity (HC3), Johns Hopkins School of Public Health Center for Communication Programs, Baltimore, viewed 15 March 2015, from https://www.k4health.org/sites/default/ Baltimore, viewed 15 March 2015, from
files/p_process_brochure_-_new.pdf.

Hornik, R.C., 1989, 'Channel effectiveness in development communications campaigns', Public Communications Campaigns 309-319.

Jackson, L.D. \& Duffy, B.K. (eds.), 1998, Health communication research, Greenwood, Westport, CT.

Keeney, S., Hasson, F. \& Mckenna, H.P., 2001, 'A critical review of the Delphi technique as a research methodology for nursing', International Journal of Nursing Studies 38, 195-200. PMID: 11223060.

Krenn, S. \& Limaye, R., 2009, 'The role of social and behavior change communication in combating HIV/AIDS', in R. Marlink \& S. Teitelman (eds.), From the ground up: Building comprehensive HIV/AIDS care programs in resource-limited settings, pp. 135-163, Elizabeth Glaser Pediatric AIDS Foundation, Washington, DC.

Moreno, M. \& Whitehill, J., 2014, 'Influence of social media on alcohol use in adolescents and young adults', Alcohol Research 36, 91-100.

National Cancer Institute (NCI), 1989, Making Health Communications Work Publication No. NIH 89-1493, U.S. Department of Health and Human Services (HHS), Washington, DC.

Nzioka, C., 1996, 'Lay perceptions of risk of HIV infection and the social construction of safer sex: Some experiences from Kenya', AIDS Care 8, 565-579. PMID: 8893907.

OECD, 2006, The challenge of capacity development: Working towards good practice. Organisation for Economic Cooperation and Development (OECD), viewed 15 January 2015, from http://siteresources.worldbank.org/INTCDRC/Resources/ oecd_challenge_of_capacity_development.pdf

Okidu, O., 2014, 'HIV/AIDS communication in four Nigerian mainstream newspapers', Pan African Medical Journal 17, 16.

Piotrow, P.T., Kincaid, D.L., Rimon, J.G. \& Rinehart, W., 1997, Health communication: Lessons from family planning and reproductive health, Praeger, Westport, CT.

Population Reference Bureau, 2014, World population data sheet, Population Reference Bureau, viewed 18 January 2015, from http://www.prb.org/ pdf14/2014-world-population-data-sheet_eng.pdf.

Powell, C., 2003, 'The Delphi technique: Myths and realities', Journal of Advanced Nursing 41, 376-382. PMID: 12581103.

Pyramid-Research, 2010, The impact of mobile services in Nigeria: How mobile technologies are transforming economic and social activities, Pyramid-Research, viewed 03 April 2015, from http://www.ictregulationtoolkit.org/en/toolkit/docs/ Document/3913.

Rowe, S., Alexander, N., Almeida, N.G., Black, R., Burns, R., Bush, L. et al., 2011, 'Translating the dietary guidelines for Americans 2010 to bring about real behavior change', Journal of the American Dietetic Association 111, 28-39. PMID: 21185961, http://dx.doi.org/10.1016/j.jada.2010.11.007

Sackman, H., 1975, Delphi critique, Lexington Books, Massachusetts.

Thomas, R.K., 2006, Health communication, Springer, New York.

UNDP, 2014, Human Development Report 2014: Sustaining human progress: Reducing vulnerabilities and building resilience, United Nations Development Programme, New York.

Wallack, L., 1989 , 'Mass communication and health promotion: A critical perspective', in R. Rice and C. Atkin (eds.), Public Communcation Campaign, pp. 353-367, Sage, Newbury Park, CA. 